\title{
VIABILIDADE DA INTRODUÇÃO DO MEL NA MERENDA ESCOLAR: OPORTUNIDADE E DESAFIO PARA O AGRONEGÓCIO APÍCOLA ${ }^{1}$
}

\author{
Angélica Margarete Magalhães ${ }^{2}$ \\ Roselene de Queiroz Chaves ${ }^{3}$ \\ Tânia Nunes da Silva
}

Resumo: Tendo como pano de fundo a desestabilização do mercado apícola, decorrente do bloqueio europeu às exportações brasileiras de mel, e a crescente necessidade de promover esse importante produto do agronegócio brasileiro, foi realizado este estudo, que busca avaliar a viabilidade da introdução do mel na merenda escolar, como oportunidade mercadológica dentro da abordagem teórica de Sistema Agroalimentar Local (SIAL). Avaliaram-se a aceitabilidade e o custo de aquisição do mel, comparados a outros dois equivalentes já utilizados na merenda escolar: o melado de cana-de-açúcar e a geleia de frutas. Foi identificada uma aceitabilidade menor do mel em relação à geleia, com base em todas as variáveis analisadas (cor, aroma, sabor e textura), e maior em relação ao melado (exceto na variável textura). O custo de uma porção de preparação com mel $(\mathrm{R} \$ 0,26)$ ficou $18 \%$ acima do valor per capita repassado pelo FNDE (R\$ $0,26)$. Conclui-se que constituem desafios para o agronegócio apícola os trabalhos relativos à educação alimentar e promoção do produto mel junto à sociedade, a fim de aumentar sua aceitabilidade, além de uma política de preços diferenciados para a merenda escolar e uma logística de fornecimento do produto registrado bem distribuída no país.

Palavras-chave: Apicultura, alimentação escolar, teste de aceitabilidade, Sistema Agroalimentar Local (SIAL).

Recebido em 02/03/09; Aceito em 15/05/09.

2 Nutricionista, doutoranda do Centro de Estudos e Pesquisas em Agronegócios (Cepan)/ UFRGS. E-mail: vnangelica@yahoo.com.br.

3 Engenheira Agrônoma, doutoranda do Centro de Estudos e Pesquisas em Agronegócios (Cepan)/ UFRGS. Email: roselene@cnpaf.embrapa.br.

4 Professora do Centro de Estudos e Pesquisas em Agronegócios - Escola de Administração UFRGS. E-mail: tnsilva@ea.ufrgs.br. 


\section{Introdução}

A apicultura tem se consolidado como importante atividade, do ponto de vista econômico, social e ambiental, visto que é tipicamente empregadora de mão-de-obra familiar, proporciona geração de fluxo de renda e reduz a dependência dos produtos agrícolas de subsistência tradicionais, o que favorece a fixação do homem no campo. Além disso, por ser dependente dos recursos naturais, favorece a preservação da flora nativa, garantindo, também, a preservação de espécies animais dependentes dessa flora.

Desde seus primórdios, a apicultura brasileira já passou por vários desafios, caracterizados por impactos negativos e positivos que se intercalaram ao longo dos anos. Gonçalves (2006) dividiu a história da apicultura brasileira basicamente em três etapas distintas, quais sejam, a primeira etapa ou "período de implantação da apicultura no país", que corresponde ao período de 1839 a 1955 e que, portanto, antecede a chegada das abelhas africanas (Apis mellifera scutellata) no Brasil, em 1956; a segunda ou "período de africanização dos apiários e das colônias na natureza", que se iniciou, intensamente, a partir dos primeiros enxames africanos ocorridos em 1956, continuando ao longo dos anos e, ultimamente, com menos intensidade até os dias atuais; e a terceira, muito marcante, que foi o "período de recuperação e expansão da apicultura brasileira", iniciado em 1970, quando foi realizado o Primeiro Congresso Brasileiro de Apicultura, atingindo até os dias de hoje, por meio de uma série de ações em universidades e alguns órgãos governamentais, lideradas pelos pesquisadores, técnicos e apicultores, o que proporcionou importante dinâmica para o agronegócio apícola.

Segundo estimativas dos distintos estados brasileiros, a produção média anual de mel, no Brasil, aumentou consideravelmente, visto que atingiu 40 mil toneladas nos últimos anos, embora ainda não exista uma estatística exata nem da produção, nem do número de apicultores e de colmeias no país. As estimativas do último levantamento oficial (IBGE, 2004) apontam uma produção nacional da ordem de 32.290,5 toneladas, e o Rio Grande 
do Sul é o maior produtor. A Figura 1 apresenta a produção brasileira de mel em toneladas, na região e no estado (última pesquisa oficial).

Até cinco anos atrás, a exploração de produtos apícolas, representada majoritariamente pelo mel, era inexpressiva, se comparada ao mercado mundial, dado o preço praticado que não estimulava o aumento da produção. Com a ocorrência de problemas que envolviam dois dos principais fornecedores mundiais em meados de 2000 (China e Argentina), houve forte queda na oferta do produto no mercado internacional, o que deu o impulso necessário à explosão da produção de mel no Brasil. Com a volta desses países no cenário internacional, o preço tendeu a voltar ao seu patamar histórico, ficando entre US\$ 0,90 e US\$1,00 o quilograma de mel. Esse movimento reduziu, claramente, as margens de ganho apresentadas nos últimos cinco anos, o que demandou de apicultores e empresas exportadores melhorias no processo produtivo e nas relações de compra e venda, para que a apicultura nacional seguisse na sua trajetória de crescimento.

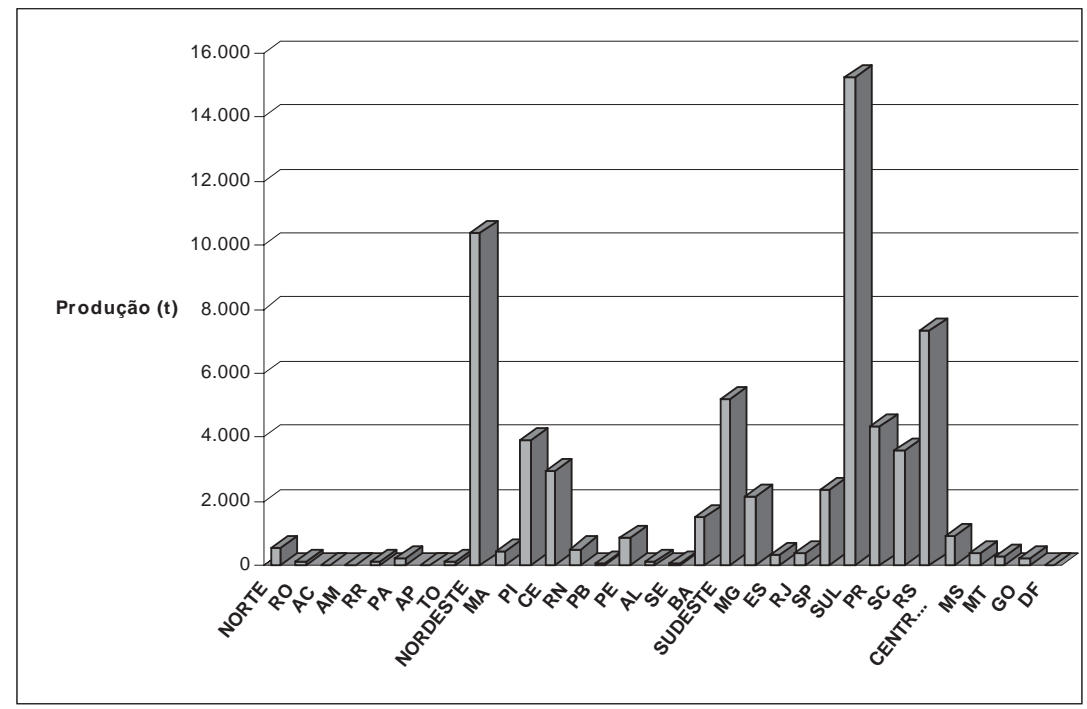

Figura 1 - Produção brasileira de mel em toneladas, em nível regional e estadual.

Fonte: IBGE, 2004. 
Outra ameaça recente ao bom andamento do mercado apícola nacional foi o bloqueio europeu às exportações brasileiras, a partir de março de 2006, quando foram concedidos seis meses para que o MAPA reestruturasse o Programa Nacional de Controle de Resíduos (AGROANALYSIS, 2006). O impacto desse embargo foi considerável, dado que mais de $70 \%$ das exportações brasileiras (que totalizaram 14,4 mil toneladas em 2005) foram destinadas à União Européia.

Tendo em vista esse cenário, as soluções para a crise deverão ser encontradas no mercado interno. Sabe-se que no Brasil, de forma geral, o consumo per capita anual fica entre 250 e 300 gramas entre a classe alta e média. No Sul, esse valor sobe para 400 gramas/ano, caindo para somente 150 gramas/ano na região Nordeste. Esses valores são muito reduzidos em relação aos de outros países. Por exemplo, na Alemanha, o consumo médio per capita é de 3.000g (REIS, 2003). Nesse sentido, algumas associações de apicultores já vêm lutando pela inclusão do mel na merenda escolar. $\mathrm{O}$ aumento no consumo interno faz com que o país se torne menos vulnerável às oscilações do mercado externo. Além disso, o envio do mel fracionado para União Européia tem uma série de fatores complicadores, razão pelo qual o referido produto deve ser direcionado ao mercado interno, que é realmente um grande consumidor potencial.

A exploração do mercado interno deve acontecer dentro de configurações socioprodutivas que proporcionem vantagem competitiva para a cadeia produtiva do mel, como, por exemplo, o Sistema Agroalimentar Local SIAL (REQUIER-DESJARDINS, 1999 e 2002). Segundo Lins (2004), o espaço do SIAL, além do conteúdo geográfico, é construído por ações coletivas, marcadas por questões culturais e regulado institucionalmente. O que ocorre é uma interação entre território e cadeia produtiva (produção-distribuição-consumo) de determinado alimento. Esse espaço de cooperação cria oportunidades e novos caminhos para a atuação dos produtores no ambiente competitivo, principalmente pela redução dos custos de transação e pela alta especificidade dos ativos presentes no território (REQUIER-DESJARDINS, 1999). 
Uma estratégia que se mostra viável, no médio prazo, é estimular o aumento do consumo por meio de campanhas para introdução do referido alimento nas refeições diárias da população. Uma ação importante, realizada por algumas prefeituras, é a introdução de sachês de mel na merenda escolar do município, com consumo diário estimado em $10 \mathrm{~g} /$ aluno/dia. Não obstante a possibilidade de introdução do mel na merenda escolar, há outras estratégias a serem implementadas junto ao mercado interno, tais como criação e divulgação de catálogos sobre mel e derivados de cada região de produção, destacando sua importância para a alimentação humana.

No Brasil, a Instrução Normativa n. ${ }^{\circ}$ 11, de 20/10/2000, do Ministério da Agricultura, Pecuária e Abastecimento, descreve detalhadamente as normas de produção, tipificação, processamento, envase, distribuição, identificação e certificação da qualidade para o mel, que é definido como o produto alimentício produzido pelas abelhas melíferas a partir do néctar das flores ou das secreções procedentes de partes vivas de plantas ou de excreções de insetos sugadores de plantas que ficam sobre partes vivas de plantas, que as abelhas recolhem, transformam, combinam com substâncias específicas próprias, armazenam e deixam maturar nos favos da colmeia (BRASIL, 2000). Essa normativa define a composição do mel como uma solução concentrada de açúcares, com predominância de glicose e frutose. Contém, ainda, uma mistura complexa de outros hidratos de carbono, enzimas, aminoácidos, ácidos orgânicos, minerais, substâncias aromáticas, pigmentos e grãos de pólen que podem conter cera de abelhas procedente do processo de extração.

Um grande entrave ao incremento do consumo é o fato de o brasileiro, de forma geral, considerar o mel apenas um medicamento natural útil para as vias respiratórias. No entanto, ele é um alimento rico em nutrientes, pois apresenta grandes quantidades de açúcares e menores quantidades de minerais, ácidos orgânicos, proteínas e vitaminas (EBELING, 2002). 
Segundo Assis (2001), a rápida urbanização, o êxodo rural e a concentração populacional desordenada nas grandes metrópoles determinaram grandes transformações no modelo alimentar do brasileiro, levando-o ao consumo excessivo de alimentos refinados, com pouca fibra, muita sacarose e gordura. Esse modelo alimentar é percebido tanto nas populações de baixa renda (não apenas por serem alimentos mais baratos, mas porque a baixa renda está geralmente associada à falta de acesso à educação, o que dificulta a escolha adequada de alimentos), quanto em populações de classe média, provavelmente influenciadas pelo processo de industrialização, urbanização e modismos (SCHRAMM, 2004). No entanto, os novos padrões alimentares impostos pela modernidade têm levado a um desequilíbrio nutricional da alimentação, com consequente aumento na prevalência de doenças crônicas não transmissíveis, como obesidade, diabetes, hipertensão e doenças cardiovasculares (DUTRA; CUNHA, 1996; ASSIS, 2001; MARTINS, 1997).

Segundo o Guia Alimentar para a População Brasileira, do Ministério da Saúde (BRASIL, 2005), o mel encontra-se no grupo dos açúcares e doces. A alimentação de crianças com idade escolar deve conter uma porção diária desses alimentos, a qual deve fornecer cerca de 5\% das calorias diárias, o que representa, para crianças eutróficas, em torno de 110 calorias/dia. De acordo com Philippi (2001), para fornecer 110 calorias, são necessários 37,5g de mel, o que equivale a $21 / 2$ colheres de sopa. As porções de alimentos substitutos que pertencem ao mesmo grupo são $28 \mathrm{~g}$ de açúcar refinado, $25 \mathrm{~g}$ de açúcar mascavo, $45 \mathrm{~g}$ de goiabada em pasta. Já Pinheiro et al. (2005) acrescentaram, além desses alimentos, a equivalência de $32 \mathrm{~g}$ de melado de cana-de-açúcar e $34 \mathrm{~g}$ de geleia de frutas.

Para crianças menores de um ano, o consumo de mel, assim como o de todos os outros alimentos do grupo de açúcares e doces, é contraindicado, salvo em situações de demanda energética aumentada (OPAS/MS, 2002).

O Programa de Alimentação Escolar pode ser um importante mercado para o mel, uma vez que um dos princípios norteadores do processo de aquisição de alimentos é dar prioridade a produtos brasileiros, 
preferencialmente regionais e oriundos da agricultura familiar (FNDE, 2006). No entanto, para sua inclusão em Programas de Alimentação Escolar (PAE), deve ser feita uma análise prévia, considerando variáveis como aceitabilidade e custo (CALIL; AGUIAR, 1999).

O Programa Nacional de Alimentação Escolar (PNAE), implantado em 1955, é reconhecido pela UNICEF como o maior projeto de alimentação do mundo. É o mais antigo programa social do Governo Federal Brasileiro na área da Educação, visto que atende, durante os 200 dias letivos, a 37 milhões de crianças e adolescentes por dia, que constituem $21 \%$ da população brasileira, com orçamento de $\mathrm{R} \$ 1,5$ bilhão no ano de 2006 (FNDE, 2006). Segundo Bulos (2000), esse direito está previsto no artigo 208, inciso VII da Constituição Federal, quando coloca que o dever do Estado com a educação é efetivado pela garantia de "atendimento do educando até o ensino fundamental, através de programas suplementares de material didático-escolar, transporte, alimentação e assistência à saúde" (inciso VII).

O PNAE atende a alunos da educação infantil (creches e pré-escola) e do ensino fundamental, inclusive das escolas indígenas, matriculados em escolas públicas e filantrópicas. Seu objetivo é suprir as necessidades nutricionais dos alunos durante a permanência destes em sala de aula, contribuindo para o crescimento, desenvolvimento, aprendizagem e rendimento escolar dos estudantes, bem como para a formação de hábitos alimentares saudáveis. Os recursos financeiros desse programa têm caráter suplementar e destinam-se à aquisição de gêneros alimentícios.

A direção das escolas públicas planeja o cardápio de acordo com a verba disponível, que é repassada com base no censo escolar e é orientada para dar preferência aos alimentos regionais, possibilitando, assim, melhor aceitação da merenda, bem como maior incremento na renda local pela produção de alimentos regionais, sendo, atualmente, repassado para cada estudante o valor de $\mathrm{R} \$ 0,22$ (vinte e dois centavos de reais)/dia. Para os alunos das escolas indígenas e localizadas em comunidades quilombolas, o valor per capita é de $\mathrm{R} \$ 0,44$ (quarenta e quatro centavos de reais)/ dia. 
O cardápio da merenda escolar, sob responsabilidade das entidades executoras, deve ser elaborado por nutricionistas habilitados e programado para suprir, no mínimo, $15 \%$ das necessidades nutricionais diárias dos alunos beneficiados, sendo que $70 \%$ dos recursos devem ser gastos na aquisição de alimentos básicos. Essa proposta (15\% das necessidades nutricionais) do PNAE é baseada na Recommended Dietary Allowances (NRC, 1989), sendo essas também as mesmas recomendações referidas na Portaria ${ }^{\circ}$ 33, da Agência Nacional de Vigilância Nacional (ANVISA, 2003).

As exigências nutricionais devem ser atendidas em todos os parâmetros (energéticos, proteicos, lipídicos, vitamínicos, minerais e de fibra), de modo a promover hábitos alimentares saudáveis, respeitando-se a vocação agrícola da região, os produtos regionais locais e a preferência por produtos básicos.

A aceitação de um alimento pelo aluno é o principal fator que determina a qualidade do serviço prestado pelas escolas, no tocante ao fornecimento da merenda escolar. Segundo as normas do PNAE, as instituições de ensino deverão aplicar teste de aceitabilidade, sempre que houver no cardápio a introdução de alimento atípico ao hábito alimentar local ou quaisquer outras alterações inovadoras, no que diz respeito ao preparo, ou para avaliar a aceitação dos cardápios praticados frequentemente. A própria instituição pode definir a metodologia do teste, ao observar parâmetros técnicos, científicos e sensoriais reconhecidos, desde que o índice de aceitabilidade não seja inferior a $85 \%$ (oitenta e cinco por cento).

Para averiguar a aceitação de determinado alimento, a pesquisa sobre preferência e aceitação da merenda escolar é um instrumento fundamental, pois é de fácil execução e permite verificar a preferência média dos alimentos oferecidos (CALIL; AGUIAR, 1999).

Este trabalho objetivou avaliar a viabilidade da introdução do mel na merenda escolar, por meio do teste de aceitabilidade (variáveis como cor, aroma, sabor e textura) e avaliação do custo de utilização deste produto em uma preparação (pão com mel) servida e avaliada junto a 
uma amostra dos alunos da rede municipal de ensino de Sentinela do Sul, RS. A partir dos resultados obtidos, foi feita uma análise dos desafios a serem enfrentados pelo agronegócio apícola para introdução do mel no Programa Nacional de Alimentação Escolar.

\section{Metodologia}

O presente trabalho foi desenvolvido na Rede Municipal de Ensino Fundamental de Sentinela do Sul, RS, que atende a um total de 398 crianças de $1^{\mathrm{a}}$ a $8^{\mathrm{a}}$ série, distribuídas em nove escolas localizadas nas diferentes regiões do município. Esse município foi selecionado por ter iniciado a implantação de um modelo de Programa de Alimentação Escolar baseado nas diretrizes do Fundo Nacional para o Desenvolvimento da Educação, do Ministério da Educação. Entre outras ações, o município contratou um profissional nutricionista, que iniciou um trabalho para verificar a aceitabilidade, o valor nutricional e o custo de diversas fontes alimentares, com vistas em estabelecer uma relação custo/benefício para embasar o processo de tomada de decisão na aquisição dos produtos alimentícios que comporão a Pauta de Alimentos do Programa Municipal de Alimentação Escolar.

O plano de amostragem foi estabelecido de acordo com o proposto por Barbetta (2001), com seleção de amostra aleatória simples, sendo o número de participantes calculado com um erro amostral tolerável de 4\%. Assim, o número de participantes (n) foi igual a 91 crianças, o que representa 23 $\%$ do total de alunos matriculados $(\mathrm{N})$.

Foi elaborado um cardápio com opção pelo mel, em vez de geleia de frutas e melado, servido sobre fatias de pão de forma, nas proporções estabelecidas por Pinheiro et al. (2005).

A primeira etapa da pesquisa foi realizada em cozinha experimental, de acordo o método proposto por Calil e Aguiar (1999), e as quantidades, em gramas, foram convertidas em medidas caseiras. A partir daí, foram 
calculados o valor nutricional e o custo de cada preparação, sendo considerada como porção um "sanduíche" composto por duas fatias de pão de forma recheadas com o respectivo doce, em quantidade suficiente para espalhá-lo sobre uma das fatias.

A gramatura per capita de doce foi determinada a partir da diferença de peso do pão sem o recheio e após a adição de uma porção de recheio. $\mathrm{O}$ instrumento utilizado nessa verificação foi uma balança de precisão, com capacidade para um quilograma e variação de um grama.

No cálculo do valor nutricional foram utilizados o programa (software) Diet Win e as informações nutricionais contidas na ficha técnica dos produtos, a qual foi fornecida pelos fabricantes. $\mathrm{O}$ custo foi calculado com utilização de planilha eletrônica, baseado no preço mínimo cotado em três orçamentos feitos para cada produto e no preço pago pelo pão licitado pelo município no primeiro semestre de 2006 , que é de $\mathrm{R} \$ 2,90$ o quilo.

A embalagem selecionada para aquisição do produto (mel) foi pote plástico hermético, com capacidade de um quilograma. Essa embalagem foi selecionada por adaptar-se melhor à manipulação, sem comprometer a qualidade do produto no armazenamento. Embalagens maiores, que permanecem com produto por mais tempo depois de abertas, favorecem a infestação de insetos como formigas e abelhas.

Na segunda etapa, foi feita a análise da aceitabilidade. Para isso, os cardápios foram preparados nas escolas e servidos aos 91 estudantes que foram previamente treinados para responder ao teste de aceitabilidade, utilizando Escala Hedônica Facial de cinco pontos e quatro variáveis, adaptada de Magalhães et al. (2005). No início de cada teste, as crianças eram previamente instruídas, e a participação era voluntária. Não houve problemas. Os cinco pontos (faces) da escala adotada corresponderam a zero, 25, 50, 75 e 100\% de aceitabilidade (Figura 2).

As características essenciais de uma escala hedônica são a suposição de preferência contínua e o estabelecimento de uma série de categorias 
sucessivas de respostas, como "gostar e não gostar" (TEIXEIRA; MEINERT; BARBETTA 1987). Uma variação da escala hedônica é a Escala Hedônica Facial (Facial Hedonic Scale) ou Escala de Avaliação de Sorriso (Smiley Rating Scale), que pode ser encontrada com 5, 7 e 9 diferentes expressões faciais (VIEIRA, 1981). Ela foi criada para superar os problemas de comunicação e semântica presentes na escala verbal. O método de escala hedônica está baseado na convicção de que respostas diretas, dadas com base em sensações, são mais válidas para predizer o comportamento real para com o alimento do que respostas mais dependentes de raciocínio. Tanto a escala quanto as instruções são designadas para uso com indivíduos inteiramente sem experiência em testes de alimentos (GARRUTI, 2003). Quando cuidadosamente instruída, a criança usa bem essas faces e responde mais rapidamente, do que quando palavras ou números são usados (FLAVIO; BARCELOS; LIMA, 2004).

A metodologia utilizada neste estudo, com vistas em avaliar a viabilidade da introdução do mel na merenda escolar, foi empregada dentro da abordagem teórica de Sistema Agroalimentar Local (SIAL), ou seja, dentro da idéia da existência de uma coordenação local da cadeia produtiva do mel, visando ao desenvolvimento de relações entre o produtorconsumidor, com potencial para facilitar novas conquistas, essenciais à eficiência coletiva e à sustentabilidade desse agronegócio (VELARD et al., 2002). 


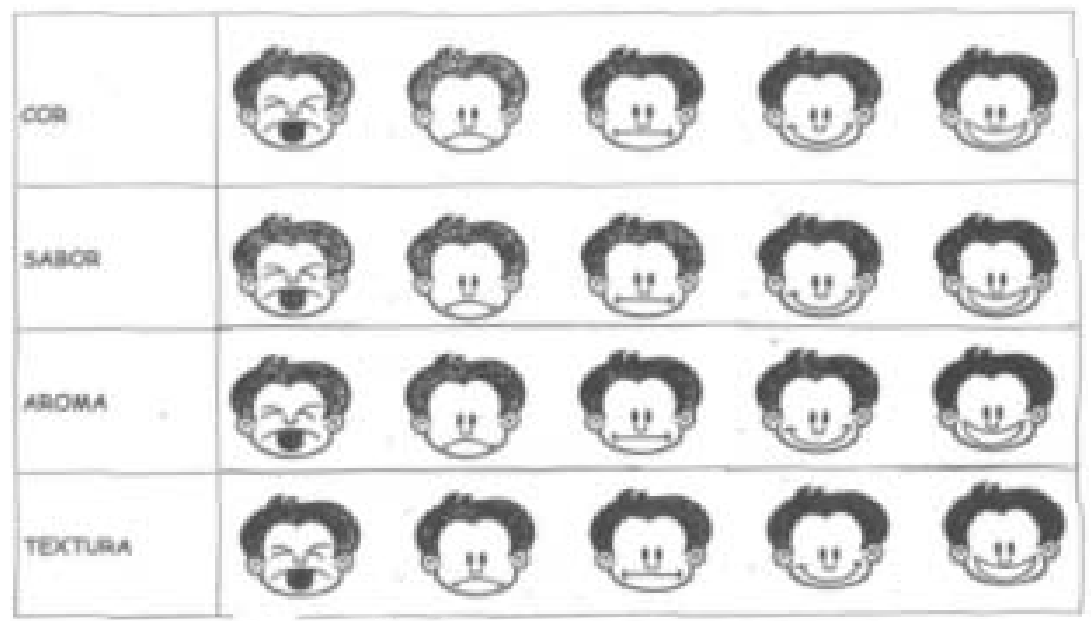

Figura 2. Escala Hedônica Facial de cinco pontos e quatro variáveis utilizadas neste estudo.

Fonte: Magalhães et al., 2005.

\section{Resultados e discussão}

Com base na contextualização do agronegócio apícola, o mel mostra-se como um potencial contribuinte para o desenvolvimento econômico regional sustentável, dadas as seguintes características de sua produção: benefícios sociais (fixação do homem no campo, emprego da mão-deobra familiar e melhoria da alimentação), impactos econômicos (geração de renda, o que reduz a dependência da agricultura de subsistência; ativação do comércio local e dos produtos direta ou indiretamente relacionados com a atividade apícola, além da ampliação da base de exportação para a economia do Estado), benefícios ambientais (preservação da flora nativa, garantindo, também, a preservação de espécies animais dependentes desta flora), e impacto social (que propicia ao produtor rural e a sua família a oportunidade de maior participação social, dignidade e qualidade de vida), ou seja, é um importante produto a ser considerado no portfólio de diversificação do agronegócio brasileiro. 
Quando se avalia a viabilidade da introdução do mel na merenda escolar, a partir da metodologia empregada neste trabalho, verifica-se a necessidade de se levarem em conta alguns fatores-chave. Na Tabela 1 , pode-se notar que a quantidade de mel per capita, necessária para compor o cardápio estudado, foi $11,8 \%$ menor que a quantidade de geleia e 6,3\% menor que a quantidade de melado. Todavia, se for feita uma suposição de implementação dessa preparação (pão com mel), pelo PAE, em nível nacional, servindo-a duas vezes por semana para os 37 milhões de crianças atendidas, no ano letivo haveria uma demanda de 31.714 toneladas, o que corresponderia a $98 \%$ da produção nacional. Deve-se levar em consideração, aqui, o fato das exigências do PNAE para com rotulagem e certificação do produto adquirido, o que ainda não ocorre para a totalidade do mel comercializado, por ser produzido em vários locais, de maneira ainda bastante artesanal.

Tabela 1 - Gramatura per capita dos componentes da preparação testada

\begin{tabular}{lc}
\hline Produto & Peso per capita $(\mathrm{g})$ \\
\hline Mel & 15 \\
Geleia & 17 \\
Melado & 16 \\
Pão & $50(2$ fatias x 25) \\
\hline
\end{tabular}

Fonte: elaborado com base na pesquisa.

Na Tabela 2, podem ser verificados os preços cotados dos três diferentes fornecedores de gêneros alimentícios do município, aos quais foi solicitado orçamento dos produtos utilizados nos preparos. Ao avaliar os dados do terceiro orçamento (preço 3), que foi escolhido por ser o mais barato, observa-se que o preço do quilo do mel foi $33 \%$ superior ao preço do quilo de geleia e $40 \%$ superior ao quilo do melado. 
Tabela 2 - Cotação de preços junto a três fornecedores da região de estudo

\begin{tabular}{lccc}
\hline Produto & Preço $1(\mathrm{R} \$ / \mathrm{Kg})$ & Preço $2(\mathrm{R} \$ / \mathrm{Kg})$ & Preço 3 $(\mathrm{R} \$ / \mathrm{Kg})$ \\
\hline Mel & 9,50 & 8,00 & 7,50 \\
Geleia & 8,00 & 6,90 & 5,00 \\
Melado & 5,00 & 4,80 & 4,50 \\
\hline
\end{tabular}

Fonte: elaborado com base na pesquisa.

Embora haja variação entre os preços dos produtos, todos atenderam às especificações exigidas para o PNAE, no que diz respeito ao controle de qualidade higiênico-sanitária, e os produtos inspecionados pelos órgãos competentes apresentavam embalagens adequadas e rótulos em conformidade com a legislação, incluindo as informações nutricionais. Nas iniciativas de estímulo ao consumo de mel nos Programas de Alimentação Escolar, têm sido sugerida a utilização de embalagens individuais (sachê). Neste trabalho, não foi cotada essa forma de apresentação, por não estar disponível para compra na região em quantidade e conformidade com a legislação exigida. Cabe salientar, aqui, as exigências do PNAE com o acesso facilitado ao produto a ser adquirido para o PAE municipal e a necessidade de a compra obedecer a todos os critérios estabelecidos na Lei ${ }^{\circ} 8.666$, de 21/6/93, que trata de licitações e contratos na administração pública (FNDE, 2006).

Os resultados da Tabela 3 mostram que não há diferença entre o teor proteico das preparações, já que nenhum dos doces utilizados continha proteínas, sendo esse nutriente oriundo exclusivamente do pão. Embora houvesse diferença no valor energético, nenhuma das preparações ultrapassou o limite diário recomendado para consumo de alimentos do grupo dos açúcares e doces (110 calorias), permitindo, ainda, uma porção a mais de doce no consumo diário de alimentos, o que pode ser utilizado na forma de açúcar para adoçar uma bebida que complemente o cardápio. 
Angélica Margarete Magalhães, Roselene de Queiroz Chaves \& Tânia Nunes da Silva

Tabela 3 - Valor energético, teor de proteínas e custo das preparações testadas

\begin{tabular}{lccccccc}
\hline Preparação & \multicolumn{3}{c}{ Energia (kcal/porção) } & \multicolumn{3}{c}{ Proteínas (g/porção) } & Custo \\
\cline { 2 - 6 } & Pão & Doce & Total & Pão & Doce & Total & (R \$porção) \\
\hline Pão com mel & 152 & 47 & 199 & 4,9 & 0 & 4,9 & 0,26 \\
Pão com geleia & 152 & 52 & 204 & 4,9 & 0 & 4,9 & 0,23 \\
Pão com melado & 152 & 55 & 207 & 4,9 & 0 & 4,9 & 0,22 \\
\hline
\end{tabular}

Fonte: elaborado com base na pesquisa.

$\mathrm{Na}$ Tabela 3, verifica-se que o custo da porção da preparação com mel foi o mais caro, entre as três testadas, tendo ficado $18 \%$ acima do valor per capita repassado pelo FNDE, razão da necessidade de contrapartida financeira por parte do município para utilização desta. Cabe salientar que a preparação "pão com mel" requer o acompanhamento de uma bebida, para que o cardápio fique adequado. Soma-se a isso o fato de que, na maioria das vezes, a contrapartida do município destina-se a contemplar despesas com insumos (gás, energia, água) e com a folha de pagamento do pessoal envolvido no processo, que não podem ser pagas com recursos oriundos do FNDE.

Conforme pode ser verificado na Tabela 4, a aceitabilidade do mel, em relação às quatro variáveis analisadas (cor, sabor, aroma e textura), ficou abaixo do índice mínimo determinado pelo FNDE (85\%). Quando se compara essa aceitabilidade com a das preparações que utilizavam melado e geleia, observa-se que, em relação ao sabor, há semelhança entre mel e geleia, que tem aceitabilidade superior ao melado. Em relação ao mel, a variável com maior aceitabilidade foi textura, e a de menor aceitabilidade, o aroma. Todavia, essas características do mel variam em função de fatores como temperatura, florada e tempo de prateleira. Dessa forma, é recomendável que esse tipo de teste seja realizado mais vezes com produtos de características variadas. 
Tabela 4 - Índice de aceitabilidade por variável avaliada em cada preparação

\begin{tabular}{lcccc}
\hline Preparação & $\begin{array}{c}\text { Aceitabilidade } \\
\text { cor }(\%)\end{array}$ & $\begin{array}{c}\text { Aceitabilidade } \\
\text { aroma }(\%)\end{array}$ & $\begin{array}{c}\text { Aceitabilidade } \\
\text { sabor }(\%)\end{array}$ & $\begin{array}{c}\text { Aceitabilidade } \\
\text { textura (\%) }\end{array}$ \\
\hline Pão com mel & 75,3 & 73,6 & 76,1 & 78,7 \\
Pão com geleia & 80,2 & 87,4 & 76,4 & 81,0 \\
Pão com melado & 69,1 & 60,8 & 68,1 & 85,1 \\
\hline
\end{tabular}

Fonte: elaborado com base na pesquisa.

Tabela 5 - Índice geral de aceitabilidade das preparações

\begin{tabular}{lc}
\hline Preparação & Aceitabilidade geral (\%) \\
\hline Pão com mel & 76,0 \\
Pão com geleia & 81,2 \\
Pão com melado & 70,8 \\
\hline
\end{tabular}

Fonte: elaborado com base na pesquisa.

Conforme a Tabela 5, verificou-se que a aceitabilidade geral (incluindo todas as variáveis) da preparação com mel ficou 10,4\% abaixo do índice mínimo de aceitabilidade estipulado pelo FNDE (85\%). Para viabilizar a inclusão do mel na merenda escolar, no município de Sentinela do Sul, RS, observa-se a real necessidade, dentre outras medidas, de trabalhos de educação alimentar que promovam o mel como um alimento saudável e interessante, a fim de melhorar o índice de aceitabilidade.

A viabilidade da introdução do mel na merenda escolar, como oportunidade mercadológica para o agronegócio apícola, pode proporcionar vantagem competitiva sustentável para os agentes que se organizarem nesse sentido. Dado seu potencial de inclusão da agricultura familiar, com inclusão de mão-de-obra local e fixação de produtores na zona rural, é de esperar que ocorra uma construção coletiva na organização do agronegócio apícola, englobando tanto a organização dos produtores quanto das empresas de serviços associados, dentro de um amparo institucional. A abordagem teórica de Sistema Agroalimentar Local (SIAL) engloba a articulação desses atores, associados por suas características e seu funcionamento a um território específico. Sugerem-se, aqui, futuros trabalhos que avaliem o agronegócio apícola dentro da vertente teórica 
do SIAL e que validem a introdução do mel na merenda escolar como estímulo ao setor, mas, ao mesmo tempo, apresente alternativas de sustentabilidade do negócio no longo prazo.

\section{Conclusões}

$\mathrm{O}$ atual momento da apicultura tem exigido uma mudança de comportamento do setor, o qual tem intensificado o debate e a reflexão acerca de uma estratégia competitiva que una esforços dos principais atores (produtores, exportadores, agências de desenvolvimento). É possível que a conjuntura adversa se transforme numa oportunidade de fortalecimento do setor apícola brasileiro, principalmente se forem concentrados esforços para resolver alguns dos gargalos da cadeia produtiva do mel, como a absorção da produção nacional.

As tentativas de que sejam votadas leis de obrigatoriedade da inclusão do mel no PNAE ou no PAE de municípios e estados parecem não ser a medida mais sensata, dado que há uma série de outros fatores que se encontram regulamentados pelo FNDE, como aceitabilidade, custo e disponibilidade na região em quantidade, dentro dos padrões de qualidade (higiênico-sanitárias, rotulagem, etc) e com acesso via licitação pública.

A inclusão do mel na merenda escolar deverá tornar-se uma oportunidade para o agronegócio apícola, caso ele ocorra como uma consequência de um ousado empenho das associações, federação e demais órgãos afins no marketing desse produto, na garantia de preço justo ao produtor e mais acessíveis ao consumidor, estimulando o aumento do consumo per capita no médio prazo e criando a cultura de consumo nas refeições diárias das famílias. Dessa maneira, o incremento na aceitabilidade pelas crianças do ensino fundamental será uma consequência.

O desafio da introdução do mel na merenda escolar deverá transformarse em oportunidade, caso haja uma construção coletiva de vantagem competitiva via organização e coordenação da cadeia produtiva do mel, 
adequada à realidade dos arranjos encontrados em cada Sistema Agroalimentar Local (SIAL).

\section{Agradecimentos}

Agradecemos às valiosas contribuições do Nutricionista do Programa de Alimentação Escolar da Prefeitura Municipal de Sentinela do Sul, RS, e à Diretora da Escola Municipal de Ensino Fundamental Paulo Schmidt, de Sentinela do Sul, pelo empenho e pela mobilização dos estudantes para participarem deste estudo.

\section{Referências}

AGROANALYSIS. Mel: embarques suspensos. São Paulo: Fundação Getúlio Vargas. Vol. 26, n 4, abril de 2006. p. 16.

ANVISA - AGÊNCIA NACIONAL DE VIGILÂNCIA SANITÁRIA. Portaria n. 33, de 13 de janeiro de 2003. Disponível em: <http:// www.anvisa.gov.br/legis/portaria/33_98htm>. Acesso em: 10 jun. 2008.

ASSIS, A. M. O. Carências Nutricionais da População Brasileira. Revista Nutrição em Pauta. São Paulo, ano IX, n. 5, p. 11-15, nov-dez, 2001.

BARBETTA, P. A. Estatística aplicada às Ciências Sociais. 4 ed. Florianópolis: UFSC, 2001.338p.

BRASIL. Instrução Normativa n. ${ }^{\circ}$ 11, de 20 de Outubro de 2000. Diário Oficial, 23 de outubro de 2000. Seção 1, p.16-17. Regulamento técnico de identidade e qualidade do mel.

BRASIL. Ministério da Saúde. Guia alimentar para a população brasileira: promovendo a alimentação saudável. Brasília: Ministério da Saúde, 2005. 236p. 
BULOS, Uadi Lammêgo. Constituição Federal Anotada. São Paulo: Saraiva, 2000.

CALIL, R; AGUIAR, J. Nutrição e Administração nos Serviços de Alimentação Escolar. São Paulo: Marco Marcovich, 1999. 80p

DUTRA, O. J.; CUNHA, S. A Desnutrição dos Pobres e dos Ricos. São Paulo: Sarvier, 1996. 123 p.

EBELING, E. Exploração apícola. In: CONGRESSO BRASILEIRO DE APICULTURA, 14., 2002 Campo Grande, MS. Anais. Campo Grande: CBA: UFMS: FAAMS, 2002. p.166.

FLAVIO, E.F., BARCELOS, M.F.P, LIMA, A.L. Avaliação química e aceitação da merenda escolar de uma escola estadual de Lavras-MG. Ciênc. agrotec., Lavras, v. 28, n. 4, p. 840-847, jul./ago., 2004

FNDE - FUNDO NACIONAL DE DESENVOLVIMENTO DA EDUCAÇÃO. Merenda escolar. Disponível em: <http:// www.fnde.gov.br/>. Acesso em: 15 jun. 2008.

GARRUTI, D. Sensory profile and acceptance of "requeijão cremoso" cheese. Rev. Cien. Tecnol. de Alimentos. Vol 23, n. 3, pp 434-440. Campinas. Set-dez 2003.

GONÇALVES, L. S. Apicultura no Brasil com abelhas africanizadas. Artigo disponível em: <http://www.sebrae.com.br/br/revista_agro/3/ artigo_lionel.asp> Acesso em: 30 jun. 2008

IBGE. Pesquisa Pecuária Municipal. Produção da Pecuária Municipal 2004; Rio de Janeiro: IBGE, 2004. Disponível em: <http:// www.sidra.ibge.gov.br>. Acesso em: 15 jun. 2008.

LINS, H. Território, cultura e inovação: a ótica dos sistemas agroalimentares localizados. In: Encontro Nacional de Economia Política, 9, 2004, Uberlândia. Anais... Uberlândia: SEP, 2004. 1 CD-ROM 
MAGALHÃES, A.; COUTO, A.; HEINEN, J.; HÜLSE, S. Viabilidade de inserção da farinha de arroz no programa de Alimentação escolar no município de florianópolis. IV CONGRESSO BRASILEIRO DE ARROZ IRRIGADO. Santa Maria, 2005: UFSM, 2005. Anais...

MARTINS, C. Pirâmide de Alimentos: Manual do Educador. Curitiba: Nutroclinica, 1997. 147 p.

NATIONAL RESEARCH COUNCIL. Recommended dietary allowances. 10. ed. Washington: National Academic Science, 1989. 284 p.

ORGANIZAÇÃO PANAMERICANA DE SAÚDE (OPAS). Guia alimentar da criança menor de dois anos: bases científicas. Brasília, 2002.

PHILIPPI, S. T. Tabela de composição de alimentos: suporte para decisão nutricional. Brasília: UnB, 2001. 133p.

PINHEIRO, A.B.V., LACERDA, E.M.A., HAIMBENZECRY, E., GOMES, M.C.S., COSTA, V.M. Tabela para avaliação de consumo alimentar em medidas caseiras. Rio de Janeiro: 2005.

REIS, V. D. A. Mel Orgânico: Oportunidades e Desafios para a Apicultura no Pantanal. Corumbá: Embrapa Pantanal, 2003. 26 p. Série Documentos / Embrapa Pantanal.

REQUIER-DESJARDIN, D.Agro-industria rural y sistemas agroalimentarios localizados: cuáles puestas? In: PRODAR. X Aniversario de Prodar. Peru, 1999.

REQUIER-DESJARDIN, D. Multifonctionnalité, territoire et secteur agro alimentaire: une approche par lês "systèmes agroalimentaires localisés". France: Centre d'Economie et d'Ethique pour l'Environnement et le Développement, 2002. 
SCHRAMM, J.M.A. Transição epidemiológica e o estudo de carga de doença no Brasil. Ciência \& Saúde Coletiva, Rio de Janeiro, v.9, n. 4, p.897-908, 2004.

TEIXEIRA, E., MEINERT, E. M., BARBETTA, P. A. Análise sensorial de alimentos. Florianópolis : UFSC, 1987. 180 p.

VELARDE, I. et al. Sistemas de producción locales en el Río de La Plata, Argentina: concertación de actores, diferenciación y valorización de productos típicos. In: LINCK, T; SCHIAVO, C. (Org.). Globalizacion y território: nueva ruralidad, patrimônios colectivos y sustentabilidad en la cuenca del Plata. Montevideo: Nordan, 2002.

VIEIRA, I. C. Métodos de aceitação em merenda escolar, Universidade Estadual de Campinas, 1981. 116 p.

Abstract: Tends as backdrop the destabilization of the apiculture market due to the European blockade to the Brazilian exports of honey and growing need of promoting that important product of the Brazilian agribusiness, this study was accomplished looking for to evaluate the viability of the introduction of the honey in the school snack, as a marketing opportunity in the theory of Local Agrifood System (SIAL). The acceptability of the honey was evaluated, compared to other two equivalent already used in the school snack: the sugar-cane molasses and the jelly of fruits. It was identified a smaller acceptability of the honey in relation to the jelly for all the analyzed variables (color, aroma, flavor and texture) and larger in relation to the molasses (except in the variable texture). The cost of a preparation portion with honey $(\mathrm{R} \$ 0,26)$ was $18 \%$ above the per capita value reviewed by FNDE $(\mathrm{R} \$ 0,26)$. The conclusion is that the challenges for the apiculture agribusiness constitute: works of alimentary education and promotion of the product honey close to the society in order to increase the acceptability, besides a politics of prices differentiated for the school feeding and a logistics of supply of the product registered well distributed in the country.

Key words: beekeeping, school feeding, acceptability test, Local Agrifood System (SIAL). 
REVISTA DE ECONOMIA E AGRONEGÓCIO, VOL.7, $N^{o} 1$ 